\title{
Selection of the Optimum Carrier for Manufacturing Water-Repellent Concrete and Durability Evaluation of Cement Mortar Using It
}

\author{
Chang Bok Yoon ${ }^{1}(\mathbb{D})$ and Han Seung Lee ${ }^{2, *}$ (D) \\ 1 Architectural Engineering, Hanyang University, Seoul 04763, Korea; all4yoon@hanyang.ac.kr \\ 2 School of Architecture and Architectural Engineering, Hanyang University, ERICA, Ansan 15588, Korea \\ * Correspondence: ercleehs@hanyang.ac.kr; Tel.: +82-10-6229-9494
}

Received: 11 November 2020; Accepted: 16 December 2020; Published: 19 December 2020

\begin{abstract}
The purpose of this experiment was to complement the shortcomings of existing surface treatment methods and to implement water repellency inside concrete to prevent water penetration and improve the durability of concrete. Carriers to provide water repellency were fabricated using fly ash (FA), silica fume (SF), and natural zeolite which are used as admixtures for concrete. They were mixed with cement mortar, tested, and evaluated. The compressive strength of the water-repellent impregnated natural zeolite (ZWR) specimen was $83 \%$ of that of ordinary Portland cement (OPC), and its contact angle was found to be $124^{\circ}$. The water penetration test and chloride ion penetration test confirmed that the water absorption and total passing charge were reduced, while the porosity and pore size were improved. For the other specimens, except ZWR, water repellency was judged to be insufficient due to the low fixing ability for the water-repellent's active ingredient. The results of evaluating the physical performance and durability of cement mortar for the selection of the optimum carrier revealed that powders other than ZWR are not suitable as a material for providing water repellency to concrete.
\end{abstract}

Keywords: water repellent; impregnation; carrier; admixture; natural zeolite; durability

\section{Introduction}

Reinforced concrete structures exhibit degraded durability over time when exposed to various external environments such as chlorides, $\mathrm{CO}_{2}$, and water. When the durability of concrete is reduced, the corrosion of steel reinforcement may occur due to the penetration of deterioration factors caused by cracks and fractures on the surface. In particular, cracks in concrete and pores on the concrete surface serve as transport pathways for water and chlorides [1]. To address these problems, technologies to improve the durability of the concrete surface layer by applying liquid-type water repellents to the concrete surface without forming a separate sheet protection layer were developed as methods to reduce water penetration, and they have been used in References [2-5]. As for the specific mechanism of the surface treatment technique, a material to prevent water penetration is applied to the concrete surface, and the water-repellent active ingredient blocks water as it hardens in the pores of the concrete's surface [6]. The surface treatment technique, however, cannot prevent water penetration when cracks or fracture occurs on the concrete surface due to the various external factors, because the water penetration prevention layer on the surface is also fractured. Therefore, cost and time are required to repair or reconstruct the concrete's surface. To complement this shortcoming, if the water-repellent's performance can be implemented inside the concrete, it is possible to prevent a reduction in the durability of concrete due to the water penetration despite the occurrence of cracks and deformation. If the water-repellent's active ingredient is directly added to implement the 
water-repellent's performance inside the concrete, the cementitious material and silane/siloxane, which is the water-repellent's active ingredient, can be separated and the water-repellent active's ingredient cannot be evenly distributed inside concrete. Unlike existing surface treatment methods applied only to concrete's surface, previous studies on water repellency inside concrete are not sufficient. Therefore, in this study, water-repellent carriers were fabricated and mixed with cement mortar to prevent a reduction in the durability of concrete due to the fact of water penetration and the separation of water-repellent active's ingredient, and then tests were conducted [1]. Water repellency was provided to (1) sand, (2) silica fume (SF), (3) fly ash (FA), and (4) natural zeolite, and they were mixed with (5) cement mortar. The currently used water-based water repellent was directly mixed with cement mortar to provide water repellency. The physical properties (i.e., air content, flow, compressive strength, and surface contact angle) and durability performance (i.e., water penetration test, resistance chloride penetration resistance test, and mercury intrusion porosimetry (MIP)) of cement mortar were evaluated through tests for the selection of the optimum water-repellent impregnation powder.

\section{Theoretical Background and Consideration of Existing Literature}

\subsection{Principle of Water Repellent}

Impregnation is a technique to obtain the desired performance by adding liquid and solid substances to a porous object. Among the methods to protect concrete from water penetration, the impregnation technique limited only to the surface was researched as a method of using water repellents. This surface treatment technique that uses water repellents creates hydrophobicity by increasing the surface contact angle with water through bonding between the capillary pores on the concrete surface and the water-repellent's active ingredient without forming a separate protective layer on the concrete surface [7,8]. A water repellent cannot completely block the pores in concrete and allows the movement of air and water because the water-repellent's active ingredient is fixed on the inner surface of the pores, but waterproofing causes cracking and scaling on the concrete surface because the water that penetrated into the inside cannot move to the outside and reduces freeze-thaw resistance $[9,10]$.

\subsection{Review Existing Literature}

Silane/siloxane has been known as a protective material for concrete over the last 50 years [11,12]. Water-repellent methods based on silane/siloxane have been commonly used to prevent a reduction in the durability of concrete due to the presence of water penetration [13-15]. In 2010, Dai et al. [16] conducted research on the impregnation of the water-repellent surface to prevent water penetration and to extend the service life of reinforced concrete structures in seawater environment by examining the existing surface treatment methods. In 2013, Zhu et al. [12] conducted research on recycled aggregate concrete subjected to water-repellent treatment on the surface. In other studies, the surface contact angle was increased by improving the performance of the concrete surface layer using silane/siloxane-based water repellents, and it was confirmed that the durability performance of the surface-treated specimens improved as the strength decreased due to the increase in chloride ion penetration rate $[6,17]$. In a study by F. H. Wittmann [18] ("Chloride Penetration into Integral Water Repellent Concrete"), it was found that the addition of less than $1 \%$ silane can resist chloride penetration, but it was mentioned that the reliable content was not determined.

In another study by the same author, it was mentioned that water repellency can be provided by applying linseed oil as a water repellent [19]. The contents researched in the existing literature to provide water repellency to concrete were mostly limited to the concrete surface. In the case of direct addition, there are also insufficient studies on the determination of the water repellent content and water repellency inside concrete using carriers. 


\section{Materials and Specimens}

\subsection{Outline of Experiment}

In this study, water-repellent carriers were fabricated through impregnation and coating, and then the physical and durability performances of cement mortar were evaluated to select the optimum carrier that exhibits water repellency. Table 1 shows the outline of the experiment.

Table 1. Outline of experiment.

\begin{tabular}{|c|c|c|c|}
\hline Specimen & \multicolumn{3}{|c|}{ Experiment Level } \\
\hline \multirow{6}{*}{$\begin{array}{l}\text { OPC } \\
\text { Sand-Co } \\
\text { Silica-Co } \\
\text { FA-Co } \\
\text { WR-In } \\
\text { ZWR }\end{array}$} & \multicolumn{3}{|c|}{ Classifications } \\
\hline & \multirow{4}{*}{ Method } & & Water repellent coating \\
\hline & & & Water repellent mortar inner \\
\hline & & & Water repellent \\
\hline & & ZWR & $\begin{array}{c}\text { Natural Zeolite + water repellent } \\
\text { Impregnation }\end{array}$ \\
\hline & Curing Conditions & \multicolumn{2}{|c|}{ Under water, temperature $20^{\circ} \mathrm{C}$} \\
\hline Experiment & \multicolumn{3}{|c|}{$\begin{array}{l}\text { Physical test (compressive strength, air content, flow test, contact angle) } \\
\text { Durability test (water penetration, resistance chloride ion test, MIP) } \\
\text { Microstructures (scanning electron microscope (SEM)) }\end{array}$} \\
\hline
\end{tabular}

Experimental variables were classified into six types. In addition to ordinary Portland cement (OPC), which is the reference of the experiment results, a water-repellent was sprayed onto the fine aggregate included in cement mortar and FA, SF, and natural zeolite, which are admixtures for cement, were immersed in the water repellent to provide water repellency through coating and impregnation. In addition, the water repellent was directly mixed with cement mortar to provide water repellency. As for the experimental items, the physical properties (i.e., compressive strength, air content, mortar flow test, and contact angle) and durability test (i.e., water penetration, resistance chloride ion penetration test (RCPT), and mercury intrusion porosimetry (MIP) were compared and examined to analyze water repellency. The compressive strength was measured using a universal testing machine (UTM) at 7 and 28 days of age. The compressive strength of each cube specimen in a size of $50 \times 50 \times 50 \mathrm{~mm}$ was measured three times, and the average value was used for the analysis. In the flow test, a triangular flow cone was installed on a $30 \mathrm{~cm}$ wide flow plate, and the cone was filled with mortar. The mortar was compacted and subjected to 25 impacts, and then the diameter of the widely spread cement mortar was measured. The tests were conducted in accordance with the compressive strength and flow measurement methods for hydraulic cement mortar in KS L 5105 (Korean Industrial Standards. KS L. 5105, Testing Method for Compressive Strength of Hydraulic Cement Mortar) [20] of Korea.

\subsection{Materials}

Ordinary Portland cement (S Company, Seoul, Republic of Korea) with a density of $3.15 \mathrm{~g} / \mathrm{cm}^{3}$ was used in the experiment in accordance with ASTM C150 [21]. As for fine aggregate, fine aggregate from Korea was used based on KS L ISO 679. The fineness modulus (FM) of the fine aggregate ranged from 2.3 to 3.1, which satisfied the KS standards-the Korean industrial standards. The fine aggregate had a density of $2.5 \mathrm{~g} / \mathrm{cm}^{3}$ and a water absorption of less than $3 \%$. Fly ash with a fineness of $3000 \mathrm{~cm}^{2} / \mathrm{g}$ was used based on KS L 5405 [22]. The silica fume used met the criteria of KS F 2567(Korean Industrial Standards. KS F 2567, Standard Specification on Silica Fume for Concrete) [23], i.e., an $\mathrm{SiO}_{2}$ content of $85 \%$ or less, an $\mathrm{MgO}$ content of $5 \%$ or less, an $\mathrm{SO}_{3}$ content of $3.3 \%$ or less, and a specific surface area of $20 \mathrm{~m}^{2} / \mathrm{g}$. Table 2 shows the chemical compositions of the binders used. 
Table 2. Chemical composition of binder. Silica fume, (SF).

\begin{tabular}{cccccccccc}
\hline \multirow{2}{*}{ Name } & \multicolumn{7}{c}{ Chemical Compositions (\%) } \\
\cline { 2 - 10 } & $\mathrm{SiO}_{\mathbf{2}}$ & $\mathbf{A l}_{\mathbf{2}} \mathbf{O}_{\mathbf{3}}$ & $\mathrm{Fe}_{\mathbf{2}} \mathbf{O}_{\mathbf{3}}$ & $\mathbf{C a O}$ & $\mathbf{M g O}$ & $\mathbf{S O}_{3}$ & $\mathbf{K}_{\mathbf{2}} \mathbf{O}$ & $\mathbf{T i O}_{2}$ & etc. \\
\hline OPC & 19.74 & 5.33 & 2.93 & 61.74 & 3.78 & 2.47 & 0.89 & 0.3 & 2.82 \\
\hline FA & 52.6 & 21.4 & 9.20 & 5.01 & 2.01 & 0.27 & 1.13 & 8.38 \\
\hline SF & 92.3 & 1.4 & 0.6 & 0.5 & 0.3 & & & 4.9 \\
\hline
\end{tabular}

The natural zeolite used in the experiment was mined in Pohang, Gyeongbuk, Korea. It had a specific surface area of $15,600 \mathrm{~cm}^{2} / \mathrm{g}$ and a density of $2.3 \mathrm{~g} / \mathrm{cm}^{3}$ [1]. Table 3 shows the chemical composition (percentage) of the natural zeolite obtained by conducting $\mathrm{X}$-ray fluorescence analysis in accordance with the method specified in KS E 3076 [24]. Table 4 shows the proportions of hazardous components present in the natural zeolite. The water repellent used in the experiment was a water-based water repellent that used water as a solvent. Water repellents are divided into water-based and oil-based ones depending on the solvent. Oil-based water repellents have high performance but can be harmful to workers and the environment. In this study, an eco-friendly water-based water repellent was used due to the environmental issues. It was a water repellent with an effective ratio of $50 \%$ produced in Korea (E company, Gyeonggi-do, Korea), and its $\mathrm{pH}$ was 12. Table 5 shows the chemical composition of the water repellent used in the experiment.

Table 3. Chemical compositions of natural zeolite.

\begin{tabular}{cccccccc}
\hline \multirow{2}{*}{ Name } & \multicolumn{7}{c}{ Chemical Compositions (\%) } \\
\cline { 2 - 8 } & $\mathrm{SiO}_{\mathbf{2}}$ & $\mathbf{A l}_{\mathbf{2}} \mathbf{O}_{\mathbf{3}}$ & $\mathbf{F e}_{\mathbf{2}} \mathbf{O}_{\mathbf{3}}$ & $\mathbf{K}_{\mathbf{2}} \mathbf{O}$ & $\mathbf{N a}_{\mathbf{2}} \mathbf{O}$ & $\mathbf{C E C}$ & etc. \\
\hline Zeolite & 66.8 & 13.2 & 1.68 & 3.02 & 1.16 & 106 & 14.14 \\
\hline
\end{tabular}

Table 4. Hazardous component test of natural zeolite.

\begin{tabular}{ccccccccc}
\hline \multirow{2}{*}{ Name } & \multicolumn{7}{c}{ Chemical Compositions $(\mathbf{m g} / \mathbf{k g})$} \\
\cline { 2 - 10 } & $\mathbf{A s}$ & $\mathbf{C d}$ & $\mathbf{H g}$ & $\mathbf{P b}$ & $\mathbf{C r}$ & $\mathbf{C u}$ & $\mathbf{N i}$ & $\mathbf{Z n}$ \\
\hline Limit & 20 & 2 & 1 & 50 & 90 & 120 & 20 & 400 \\
\hline Result & & 0.64 & & & 7.87 & 4.37 & 3.75 & 23.81 \\
\hline
\end{tabular}

Table 5. Chemical compositions of water repellent.

\begin{tabular}{ccccccc}
\hline \multirow{2}{*}{ Name } & \multicolumn{5}{c}{ Chemical Compositions (\%) } \\
\cline { 2 - 7 } & Color & Kind & Effective Ratio (\%) & Diluent & Freeze Stability & pH \\
\hline Water Repellent & White & Silane-Siloxane & 50 & Water & - & 12 \\
\hline
\end{tabular}

\subsection{Specimens}

Cement mortar specimens were fabricated based on KS L5105 [20]. Table 6 shows the mix proportions of the cement mortar specimens. The water-to-binder (W/B) ratio was fixed at $50 \%$, and the ratio of cement to fine aggregate was set to 1:3. Each powder to which water repellency was provided was added to each specimen by $5 \%$ of the cement weight. The cement mortar for compressive strength measurement was fabricated in a size of $50 \times 50 \times 50 \mathrm{~mm}$, and the cube specimens were prepared without acceleration. For the durability test, cylindrical specimens in a size of $\varnothing 100 \times 200 \mathrm{~mm}$ were fabricated. After performing water curing at a relative humidity of $60 \%$ and a temperature of $20{ }^{\circ} \mathrm{C}$ for 7 and 28 days, the compressive strength test, contact angle test, water penetration test, RCPT, and MIP test were conducted. 
Table 6. Cement mortar mix proportion.

\begin{tabular}{|c|c|c|c|c|c|c|c|}
\hline \multirow{3}{*}{ Name } & \multirow{3}{*}{ W/B (\%) } & \multicolumn{6}{|c|}{ Unit Weight $\left(\mathrm{kg} / \mathrm{m}^{3}\right)$} \\
\hline & & \multirow{2}{*}{ W } & \multirow{2}{*}{$\mathrm{C}$} & \multirow{2}{*}{ S } & \multicolumn{2}{|c|}{$\begin{array}{c}\text { Carrier + Active Ingredient } \\
\text { = Admixture }\end{array}$} & \multirow{2}{*}{$\begin{array}{c}\text { Water } \\
\text { Repellent } \\
\text { Active Ingredient } \\
\qquad(\%)\end{array}$} \\
\hline & & & & & Zeolite & $\begin{array}{c}\text { Active } \\
\text { Ingredient }\end{array}$ & \\
\hline OPC & \multirow{6}{*}{50} & 255 & 510 & 1530 & & . & - \\
\hline Sand-Co & & 255 & 510 & 1530 & - & 25.5 & $5 \%$ \\
\hline Silica-Co & & 280.5 & 510 & 1530 & 25.5 & 25.5 & $5 \%$ \\
\hline FA-Co & & 280.5 & 510 & 1530 & 25.5 & 25.5 & $5 \%$ \\
\hline WR-In & & 229.5 & 510 & 1530 & - & 25.5 & $5 \%$ \\
\hline ZWR & & 280.5 & 510 & 1530 & 25.5 & 25.5 & $5 \%$ \\
\hline
\end{tabular}

Fly ash (FA)-Co, WR (water repellent)-In(inner), water-repellent impregnated natural zeolite (ZWR).

Figure 1 shows each powder with water repellency used in the experiment. For Sand-Co, the water repellent was sprayed onto fine aggregate for coating. For Silica-Co, FA-Co, and ZWR, each powder was immersed in the white water repellent at a 1:1 ratio and then naturally dried for one day to evaporate water. This was performed to provide each powder with water repellent performance by coating and impregnating only the effective components for water repellency. After, each powder was then completely dried at $100{ }^{\circ} \mathrm{C}$ for $24 \mathrm{~h}$ to remove the remaining water. The lumps were crushed then sifted through a $0.15 \mathrm{~mm}$ sieve to complete the fabrication of fine powders.

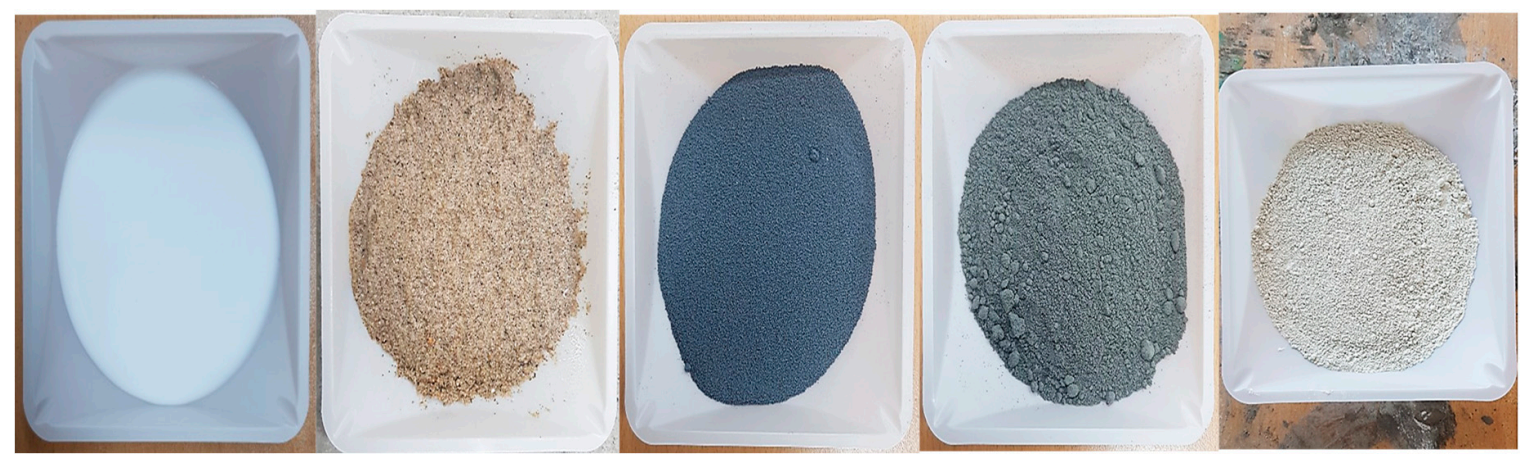

Figure 1. Water repellent coating and impregnated powder (Water repellent, Sand-Co Silica-Co, Fly ash (FA)-Co, water-repellent impregnated natural zeolite (ZWR).

\subsection{Method of Experimental}

\subsubsection{Air Content, Flow, Compressive Strength}

The compressive strength of hydraulic cement mortar was measured in accordance with KS L 5105 [20]. Based on the flow test, the air content of cement mortar was measured in accordance with KS F 2421 and ISO 4848 [25] (pressure method). Afterwards, cube specimens in a size of $50 \times 50 \times 50 \mathrm{~mm}$ were fabricated based on the specimen fabrication method for compressive strength of concrete in KS F 2405 [26] and the compressive strength test and flow test for hydraulic cement mortar in KS L 5105 [20]. The compressive strength was measured at 7 and 28 days of curing days. Figure 2 shows the air content and flow test of fresh mortar as well as the fabricated specimens. 


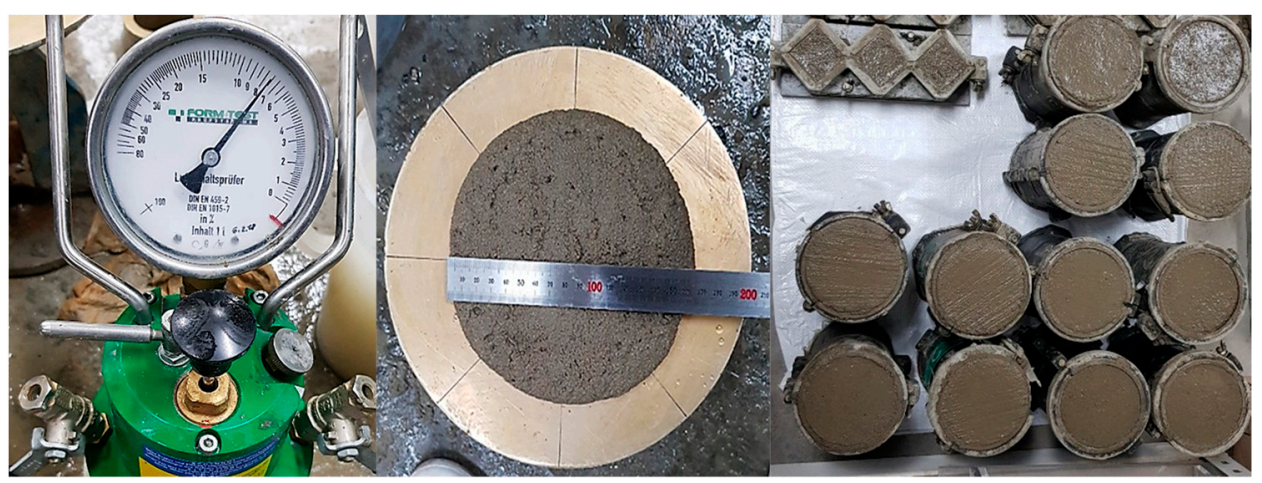

Figure 2. Measurement of air content, flow, and compressive strength specimens.

\subsubsection{Contact Angle (Sessile Drop Method)}

The sessile drop method is a typical method to obtain the surface contact angle through the surface tension of a liquid. It can obtain a more accurate value than other conventional methods by selecting an arbitrary point at which the best measurement is possible and measuring the coordinates of the point as well as the angle of the tangent [27]. Figure 3 shows the scene of measuring the surface contact angle by dropping a water drop on the specimen based on the sessile drop method.

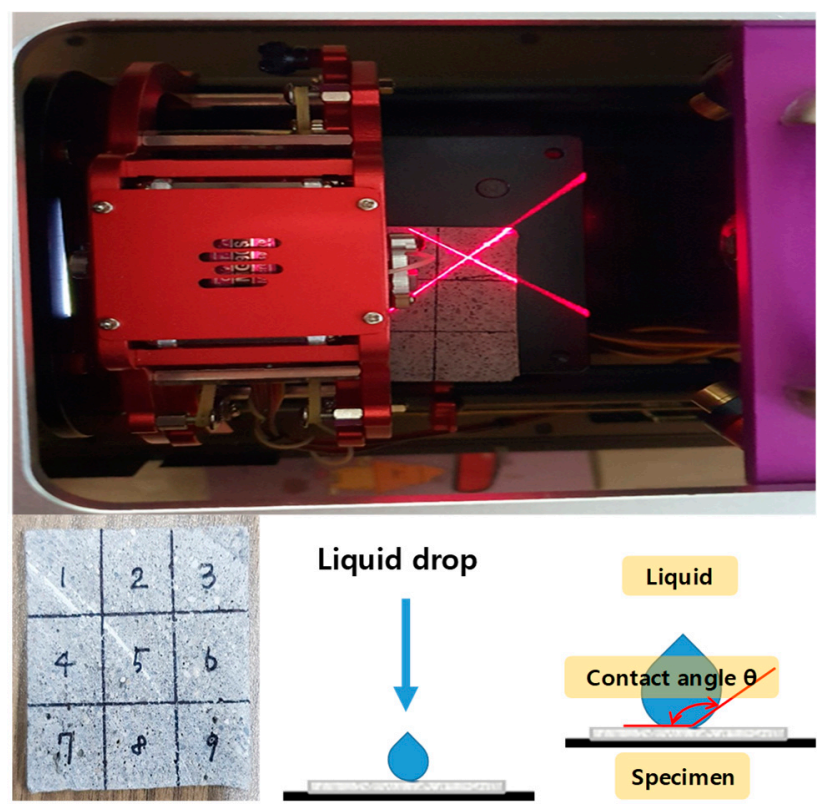

Figure 3. Measurement of contact angle.

This method can obtain results within a short period of time due to the fact of its very simple calculation process, and the reliability of the calculation results is high because the application range is wide, as there is no limit on the angle and density [27]. In general, a surface contact angle larger than $90^{\circ}$ is classified as hydrophobicity, and an angle smaller than $90^{\circ}$ as hydrophilicity [28-31]. Table 7 shows the evaluation criteria of the surface contact angle. 
Table 7. Evaluation according to chloride ion permeability.

\begin{tabular}{cc}
\hline Surface Contact Angle $(\theta)$ & Permeability \\
\hline$>130^{\circ}$ & Very good repellency \\
$110-130^{\circ}$ & Good repellency \\
$90-110^{\circ}$ & Slight wetting \\
$30-90^{\circ}$ & Pronounced wetting \\
$<30^{\circ}$ & Surface completely wet \\
\hline
\end{tabular}

\subsubsection{Water Penetration Test}

To examine the water penetration resistance of each specimen, the water penetration test was conducted in accordance with KS F 4919 "cement-containing polymer waterproofing material" [32]. Standard specimens in a size of $\varnothing 100 \times 200 \mathrm{~mm}$ were fabricated and cut to a height of $30 \mathrm{~mm}$ in the middle part. The cylindrical specimens in a size of $\varnothing 100 \times 30 \mathrm{~mm}$ were then completely dried, and the side was coated and sealed with epoxy resin so that water could penetrate from the top to the bottom surface. Immediately before the test, the weight of each specimen was measured and recorded. After connecting an air compressor to the water penetration test setup, an air pressure of $0.3 \mathrm{~N} / \mathrm{mm}^{2}$ was applied for three hours. Upon the completion of the test, the specimen was separated and wiped lightly. Its weight was then measured, and the water penetration depth was examined by splitting it at the center [1]. Figure 4 shows the water penetration test setup [1].

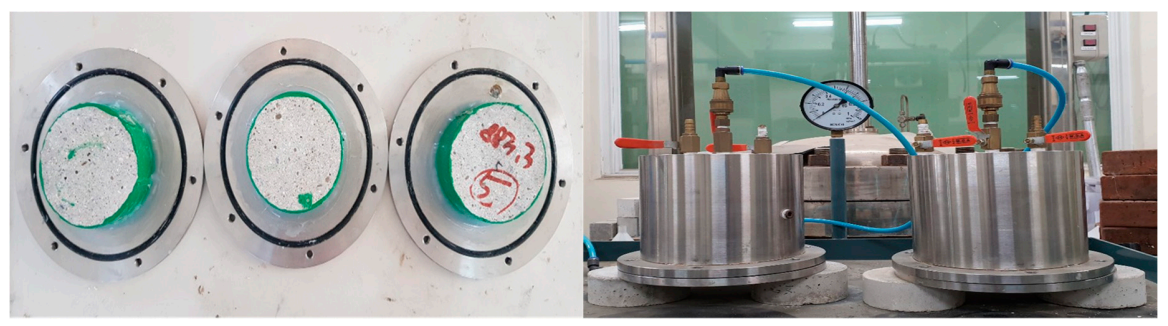

Figure 4. Water penetration test setup.

\subsubsection{Resist Chloride Ion Penetration Test (RCPT)}

The RCPT was conducted in accordance with ASTM C1202 "Standard Test Method for Electrical Indication of Concrete's Ability to Resistance Chloride Ion Penetration" (ASTM1202) [33] and KS F 2711 [34] "Concrete Chloride Ion Penetration Resistance Test Method Based on Electric Conductivity". Figure 5 shows the specimens connected to the circuit and the scene of the test.

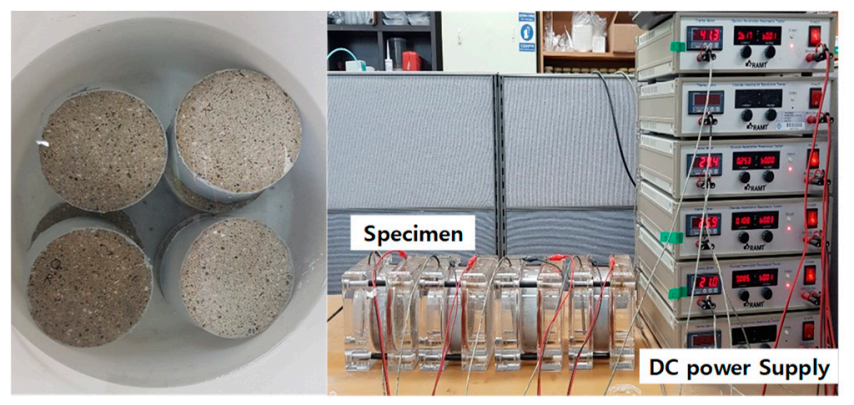

Figure 5. Specimen setup and measurement of resistance chloride ion penetration test specimen setup.

In this test, the electrical conductivity was measured to evaluate resistance to chloride ion penetration. Standard specimens in a size of $\varnothing 100 \times 200 \mathrm{~mm}$ were cut to a height of $50 \mathrm{~mm}$ in the middle part, and the side was coated with epoxy resin to prepare specimens. A $\mathrm{NaCl} 3.0 \%$ solution and a $\mathrm{NaOH} 0.3 \mathrm{~N}$ solution were prepared, and the specimens were installed in the test cells. After filling 
the anode with the $\mathrm{NaCl} 3.0 \%$ solution and the cathode with the $\mathrm{NaOH} 0.3 \mathrm{~N}$ solution, a DC voltage of $60 \mathrm{~V}$ was supplied through a voltage application device. The current was then measured every $30 \mathrm{~min}$, and the test was terminated after six hours. Table 8 shows the evaluation criteria for the passing charge according to the Coulombs value.

$$
Q=900\left(I_{0}+2 I_{30}+2 I_{60}+\cdots+2 I_{300}+2 I_{330}+I_{360}\right)
$$

Q: Total passing charge.

$l_{0}$ : Current immediately after the start of the test with voltage applied.

$l_{360}$ : Current after $360 \mathrm{~min}$ have passed after applying voltage.

Table 8. Evaluation according to chloride ion permeability.

\begin{tabular}{cc}
\hline Coulombs (C) & Permeability \\
\hline$>4000$ & High \\
\hline $2000-4000$ & Normal \\
\hline $1000-2000$ & Low \\
\hline $100-1000$ & Very low \\
\hline$<100$ & Negligible \\
\hline
\end{tabular}

\subsubsection{Mercury Intrusion Porosimetry (MIP)}

The MIP test is a widely used method to investigate the pore structure characteristics of cementitious materials. Specimens required for examination of their pore size and porosity were prepared at a size of $5 \times 5 \times 5 \mathrm{~mm}$, and the weight of each specimen ranged from 2 to $3 \mathrm{~g}$. In this study, mercury was injected at a maximum pressure of $430 \mathrm{MPa}$ at a contact angle of $130^{\circ}$ in the MIP test. The equipment used for the test was AutoPore IV series Automated Mercury Porosimeters. To ensure the same conditions for experimental analysis, samples for MIP analysis were immersed in acetone to stop hydration and then dried at $50{ }^{\circ} \mathrm{C}$ to completely remove water before the test. Figure 6 shows the equipment and specimens used in the MIP test.
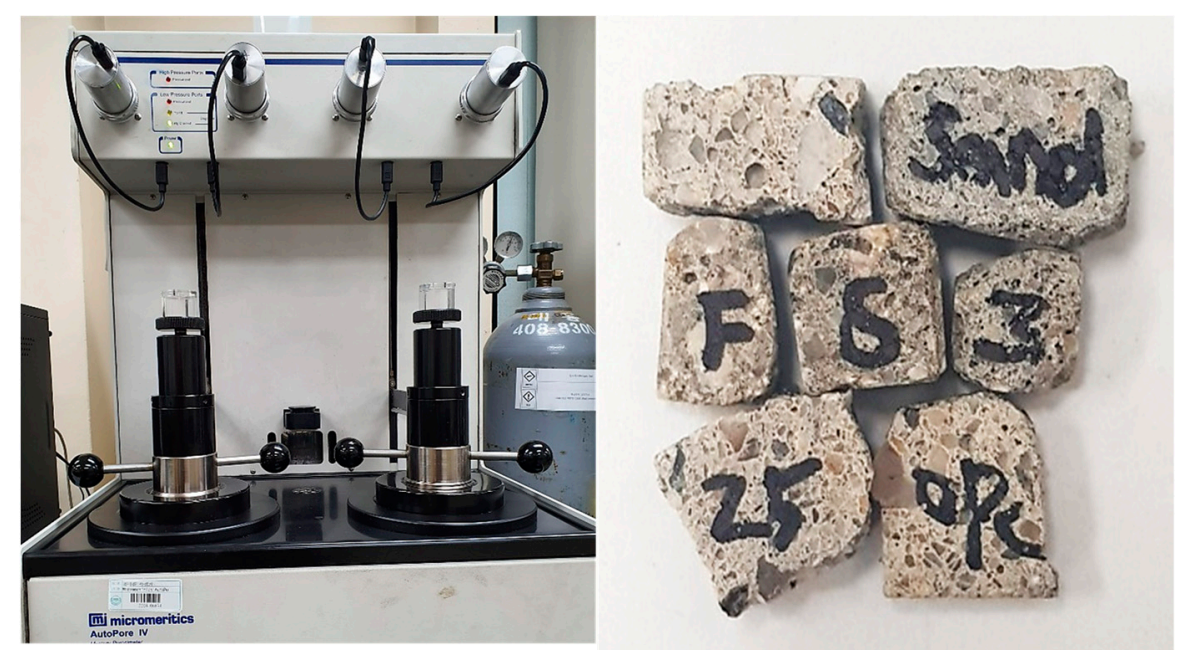

Figure 6. AutoPore IV series Automated Mercury Porosimeters.

\subsubsection{Scanning Electron Microscope (SEM)}

A SEM was used to analyze the microstructure of the cement mortar. It is a type of electron microscope that performs scanning with a focused electron beam to analyze the image of a sample. 
A SEM generates various detectable signals, including information on the surface and composition of the sample, while the electron beam interacts with the atoms of the sample. It is possible to obtain a resolution smaller than 1 nanometer with a SEM. The sand to be added to cement mortar was coated with the water repellent, and samples were collected from the specimens in which FA, SF, and natural zeolite were mixed. They were analyzed to examine the appearance of silane/siloxane inside cement mortar.

\section{Result and Discussion}

\subsection{Air Content, Flow, Compressive Strength}

To examine the physical performance of the cement mortar mixed with the water-repellent powders, the air content, flow, and compressive strength were measured. The measurement results showed that the Sand-Co, Silica-Co, FA-Co, and WR (water repellent)-In(inner) specimens exhibited approximately $60 \mathrm{~mm}$ higher flow values and higher air contents than the OPC and ZWR specimens. The compressive strengths of OPC and ZWR exhibited a standard deviation of $2 \mathrm{MPa}$, whereas those of Sand-Co, Silica-Co, FA-Co, and WR-In showed slightly larger deviations ranging from 3 to $6 \mathrm{MPa}$. The results are shown in Tables 9 and 10.

Table 9. Result of the cement mortar flow test and air content test.

\begin{tabular}{ccc}
\hline Name & Flow $(\mathbf{m m})$ & Air Content $\mathbf{( \% )}$ \\
\hline OPC & 115 & 5 \\
\hline Sand-Co & 180 & 11 \\
\hline Silica-Co & 170 & 9.5 \\
\hline FA-Co & 170 & 11 \\
\hline WR-In & 160 & 12 \\
\hline ZWR & 110 & 7.5
\end{tabular}

Fly ash (FA)-Co, WR (water repellent)-In(inner), water-repellent impregnated natural zeolite (ZWR).

Table 10. Result of compressive strength test.

\begin{tabular}{|c|c|c|c|c|c|c|c|c|c|}
\hline \multirow{3}{*}{ Name } & \multicolumn{8}{|c|}{ Compressive Strength (MPa) } & \multirow{3}{*}{$\begin{array}{c}\text { Normalized } \\
\text { Values } \\
\text { OPC } 28 \text { Days (\%) }\end{array}$} \\
\hline & \multicolumn{4}{|c|}{7 Days } & \multicolumn{4}{|c|}{28 Days } & \\
\hline & 1st & 2nd & 3rd & Average & 1st & 2nd & 3 rd & Average & \\
\hline OPC & 26 & 27.5 & 28 & 27 & 36 & 35 & 37 & 36 & 100 \\
\hline Sand-Co & 8 & 4 & 5 & 5 & 11 & 6 & 7 & 8 & 22.2 \\
\hline Silica-Co & 13 & 19 & 15 & 16 & 15 & 21 & 17 & 18 & 50 \\
\hline FA-Co & 16 & 12.5 & 13 & 14 & 18 & 12 & 16 & 15 & 41.6 \\
\hline WR-In & 10 & 10 & 13 & 11 & 7 & 9 & 13 & 10 & 27.7 \\
\hline ZWR & 25 & 25 & 23 & 24 & 30 & 29 & 32 & 30 & 83.3 \\
\hline
\end{tabular}

Fly ash (FA)-Co, WR (water repellent)-In(inner), water-repellent impregnated natural zeolite (ZWR).

Figure 7 shows the results in a graph. This appears to be because the water-repellent's active ingredient was not accurately attached to each powder, and some of it was lost as the materials were separated due to the different specific gravity of silane/siloxane, while the water-repellent's performance was left in some substances remaining inside mortar. The separated water-repellent active ingredient inhibited cement bonding at early ages, thereby causing somewhat high air content and flow values. It appears that ZWR had the ability to fix the water-repellent's active ingredient as the water-repellent's active ingredient was impregnated on the surface of and inside natural zeolite. 


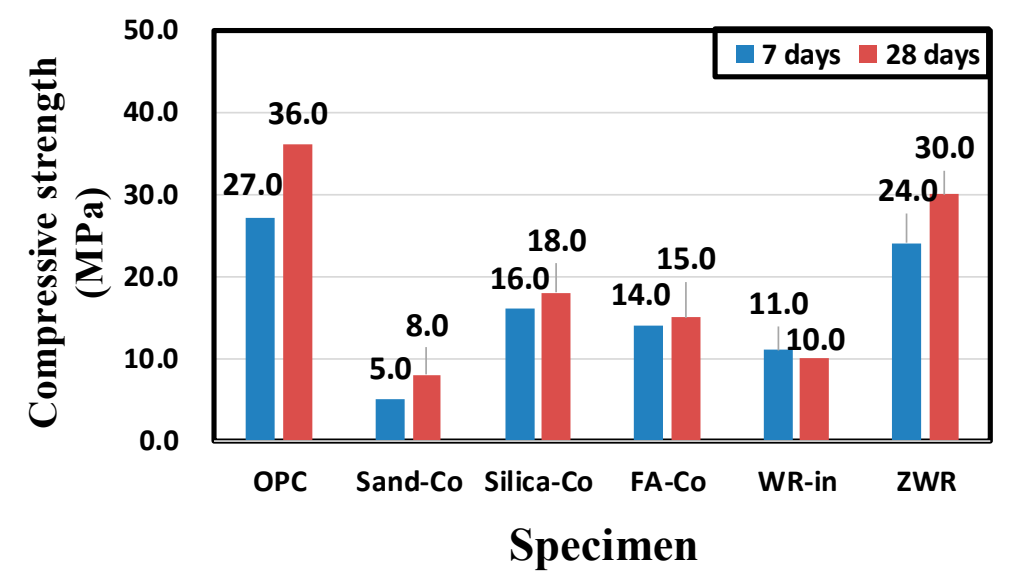

Figure 7. Results of the compressive strength test.

The OPC exhibited the highest compressive strength followed by ZWR, Silica-Co, FA-Co, WR-In, and Sand-Co. The strength of the ZWR specimen was approximately $83 \%$ of that of the reference mortar. The ZWR, which used natural zeolite as a carrier, tended to show slightly lower strength than the reference mortar. This appears to be because the fine particles of ZWR delayed the hydration reaction of cement, as it is hydrophobic and tended to be attached to the surface of the pores inside cement, and because silane/siloxane, which is the water-repellent's active ingredient, was attached to the clinker surface, thereby affecting the strengths of $C_{3} S$ and $C_{2} S$ or delaying the formation of calcium silicate hydrate (CSH) [35]. The ZWR, which used natural zeolite, can improve long-term strength and the pozzolanic reaction can be expected. The ZWR, however, does not completely contribute to the pozzolanic reaction, because the surface and outside of natural zeolite was composed of silane/siloxane through impregnation.

\subsection{Contact Angle}

The middle part of each $50 \times 50 \times 50 \mathrm{~mm}$ specimen at 28 curing days was cut and its surface was divided into nine parts. After dropping a $3 \mu \mathrm{L}$ water drop on each part, the surface contact angle was measured and averaged. The WR-In exhibited the largest surface contact angle followed by ZWR, Sand-Co, FA-Co, OPC, and Silica-Co. In the surface contact angle measurement to examine the hydrophobicity of each specimen, average values were obtained based on the results of measuring the OPC specimen three times. In the case of OPC, the surface contact angle could hardly be measured because a water drop was dropped and absorbed at the same time. The standard deviation of OPC was $\pm 10^{\circ}$ and the measurements were $13^{\circ}, 24^{\circ}$, and $21^{\circ}$, respectively. When Sand-Co, Silica-Co, and FA-Co were measured using the same method, deviations of less than $\pm 15^{\circ}$ were observed. The WR-In and ZWR specimens exhibited no significant difference with deviations of $\pm 7^{\circ}$, and slight differences did not significantly reduce hydrophobicity. Table 11 shows the results of measuring the surface contact angle using the sessile drop method at 28 days of age. 
Table 11. Result of contact angle (sessile drop method).

\begin{tabular}{|c|c|c|c|c|c|}
\hline \multirow{3}{*}{ Name } & \multicolumn{4}{|c|}{ Contact Angle $\left(^{\circ}\right) 28$ Days } & \multirow{3}{*}{$\begin{array}{l}\text { Normalized Values } \\
\text { OPC } 28 \text { Days (\%) }\end{array}$} \\
\hline & \multicolumn{4}{|c|}{ Measurement Average } & \\
\hline & 1st & 2nd & 3 rd & Total & \\
\hline OPC & - & 20 & - & 20 & 100 \\
\hline Sand-Co & 85 & 80 & 72 & 79 & 395 \\
\hline Silica-Co & 20 & - & - & 20 & 100 \\
\hline FA-Co & 74 & 60 & 69 & 68 & 340 \\
\hline WR-In & 136 & 130 & 133 & 133 & 665 \\
\hline ZWR & 122 & 124 & 128 & 124 & 620 \\
\hline
\end{tabular}

Fly ash (FA)-Co, WR (water repellent)-In(inner), water-repellent impregnated natural zeolite (ZWR).

The contact angle was found to be $133^{\circ}$ for the WR-In specimen, in which the water repellent was directly mixed, and $124^{\circ}$ for the ZWR specimen. For the OPC and Silica-Co specimens, the contact angle could not be measured because it was too small, and their contact angles were determined based on the several measurements. Figure 8 shows the measured contact angles. The contact angles of the WR-In and ZWR specimens were larger than $90^{\circ}$, which indicates hydrophobicity. For these specimens, it appears that water was not absorbed through pores and the repulsive force was generated by the surface tension, because the pores inside concrete was filled with the water-repellent's active ingredient and powder.

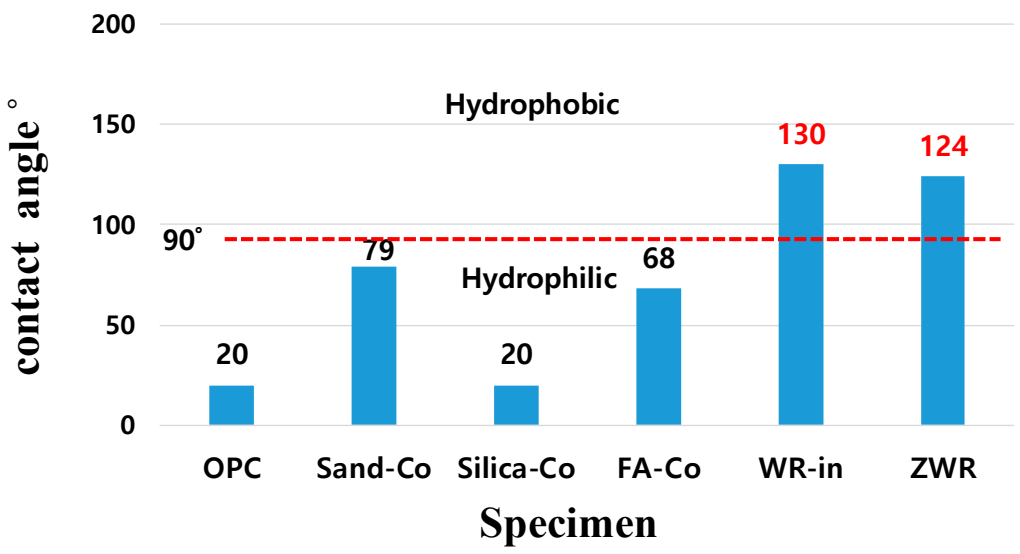

Figure 8. Result of contact angle test.

Figure 9 shows the method image of measuring the contact angle. The WR-In exhibited hydrophobicity with a contact angle of $130^{\circ}$, but its compressive strength was only $30 \%$ of that of OPC. The strength of ZWR was $83 \%$ of that of the reference sample and its contact angle was measured to be $124^{\circ}$, confirming that ZWR exhibited excellent performance compared to the compressive strength reduction rate. In the case of FA and SF, it appears that the surface was not completely coated with the water repellent even after immersion in it and drying because the surface was smooth and spherical and had few internal pores and, thus, the fixing ability was insufficient. Inside the cement mortar, some of the water-repellent's active ingredient was attached to the interface of FA and SF, and some remained in the form of particles, thereby exhibiting a small surface contact angle. It appears that the water-repellent active ingredient that remained as particles lowered the compressive strength by interfering with bonding inside cement mortar and delaying hydration. 

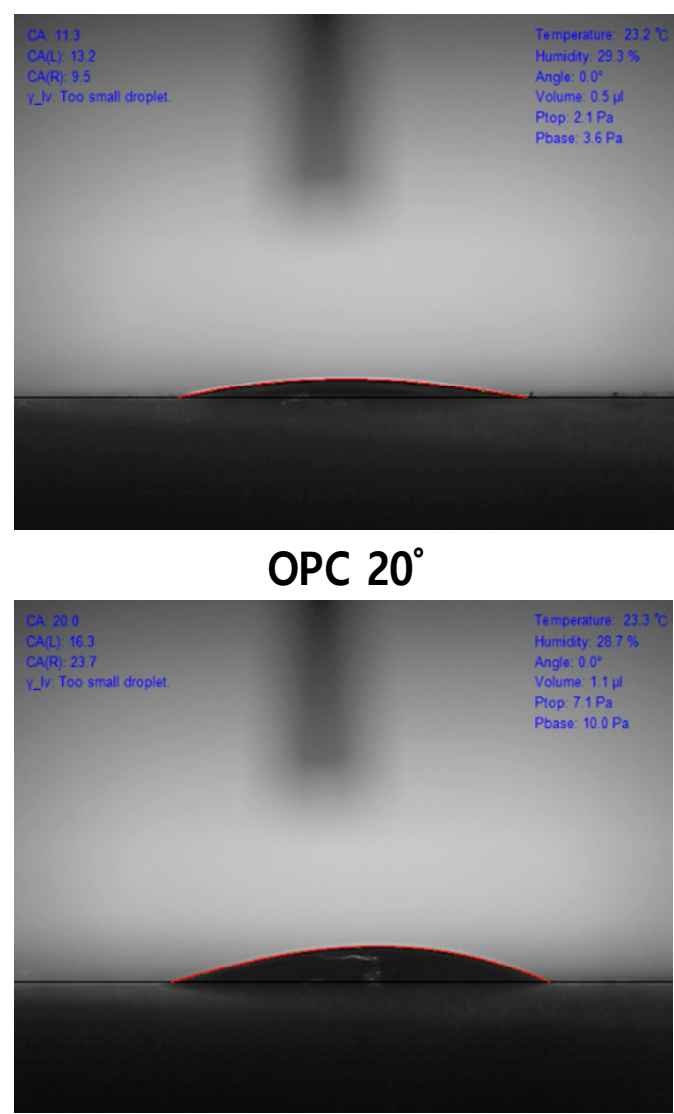

Silica-Co $20^{\circ}$

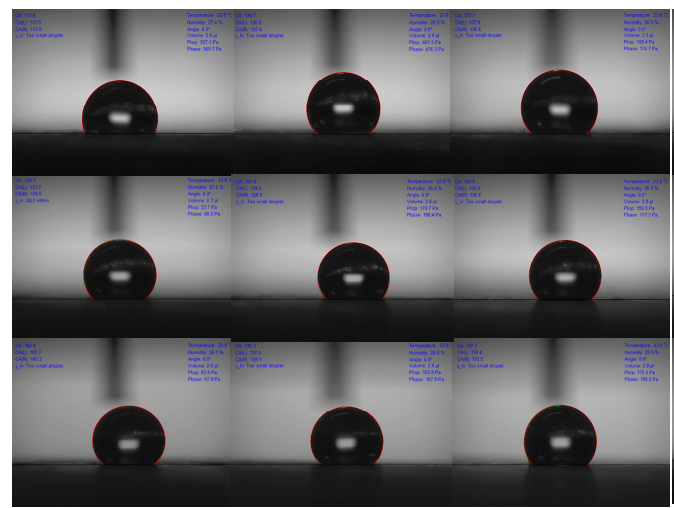

WR-In $130^{\circ}$

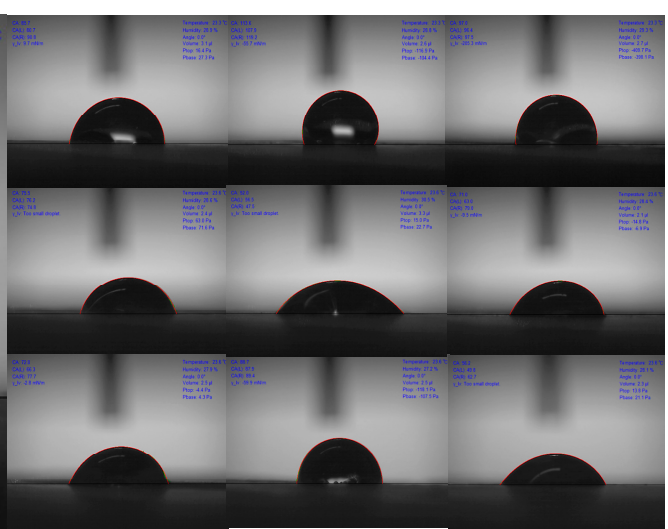

Sand-Co $79^{\circ}$

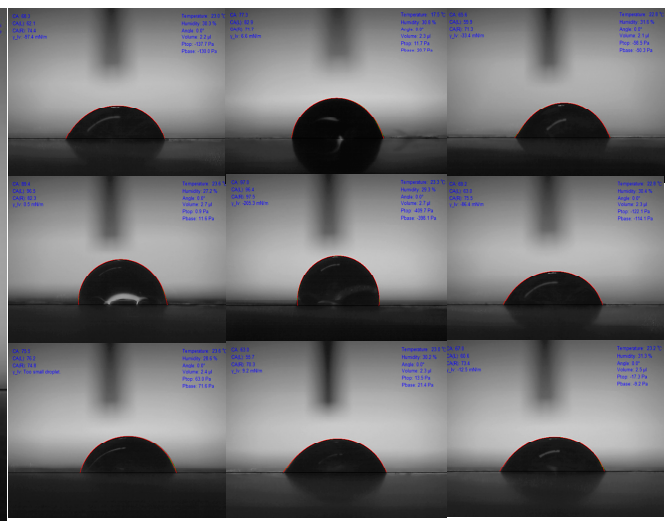

FA-Co $68^{\circ}$

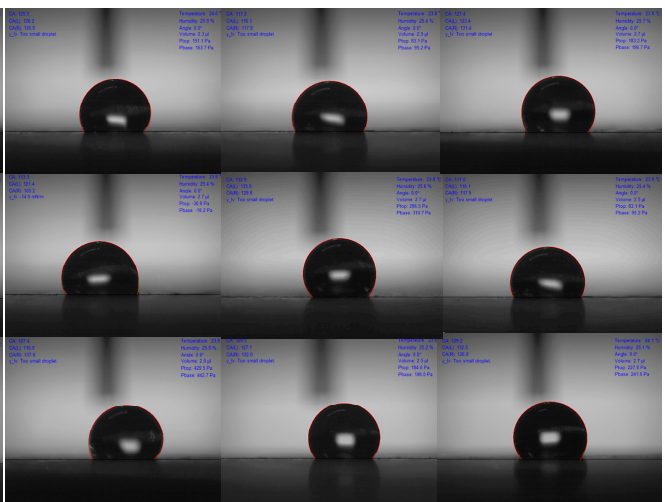

ZWR $124^{\circ}$

Figure 9. Result of the contact angle test.

\subsection{Water Penetration}

To examine the water penetration resistance of each specimen, the water penetration test was conducted in accordance with KS F 4919 [31] "cement mixed polymer waterproof material". The penetration depth was measured three times at the same atmospheric pressure using the $\varnothing 100 \times 30 \mathrm{~mm}$ specimens prepared for the water penetration test, and the average values were calculated. The test results showed that ZWR had the lowest penetration depth followed by OPC, Sand-Co, Silica-Co, FA-Co, and WR-In. For the ZWR specimen, the penetration depth difference was approximately $\pm 2 \mathrm{~cm}$, and the amount of water absorbed was $\pm 3 \mathrm{~g}$. Table 12 shows the test results, and Figure 10 shows the results in a graph. 
Table 12. Result of water penetration test.

\begin{tabular}{cccccccccc}
\hline Name. & \multicolumn{3}{c}{ Penetration Depth (mm) } & & Weight Difference (g) & \multicolumn{2}{c}{$\begin{array}{c}\text { Normalized Values } \\
\text { OPC 28 Days } \\
\text { Penetration Depth (\%) }\end{array}$} \\
\hline - & 1st & 2nd & 3rd & Average & 1st & 2nd & 3rd & Average & - \\
\hline OPC & 18.13 & 15.34 & 14.41 & 15.96 & 13.1 & 14.5 & 12.7 & 14.09 & 100 \\
\hline Sand-Co & 30 & 30 & 30 & All penetration & 25.1 & 22.6 & 27.8 & 25.1 & 188 \\
\hline Silica-Co & 30 & 30 & 30 & All penetration & 38.3 & 34.6 & 36.4 & 36.4 & 188 \\
\hline FA-Co & 30 & 30 & 30 & All penetration & 27.5 & 21.7 & 24.3 & 24.5 & 188 \\
\hline WR-In & 30 & 30 & 30 & All penetration & 31.5 & 31.6 & 34.3 & 32.5 & 188 \\
\hline ZWR & 2.9 & 2.8 & 2.3 & 2.7 & 2.1 & 1.6 & 1.5 & 1.7 & 16.91 \\
\hline
\end{tabular}

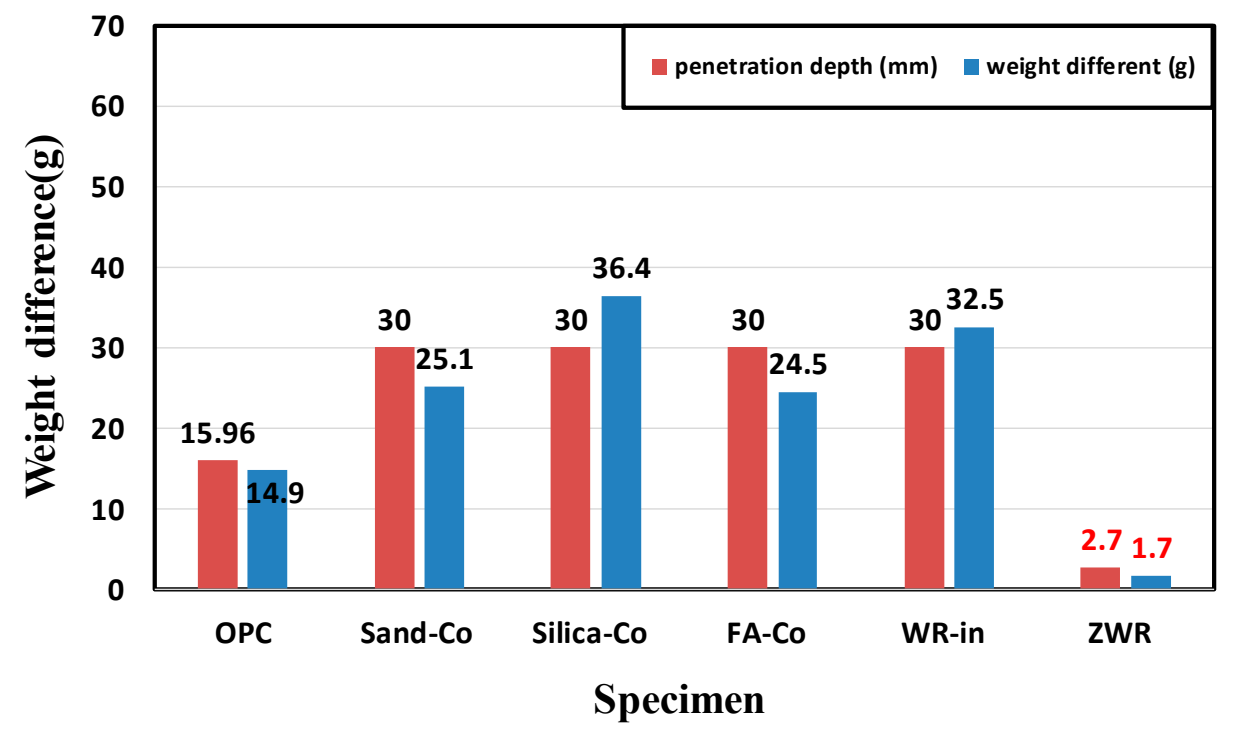

Figure 10. Result of water penetration test graph.

The test results showed that ZWR absorbed little water and the specimen exhibited no significant weight change. This appears to be because ZWR was evenly dispersed inside and the ZWR powder filled the micropores, thereby inhibiting water penetration. Meanwhile, for other specimens, it was judged that silane/siloxane did not penetrate into the mixture. Some of the water-repellent active ingredient attached only to the surface inhibited the bonding of cement, and it increased pores as it was left in pores that were not filled with hydration products.

Water penetrated all the specimens except the ZWR and OPC specimens, and they could not withstand an atmospheric pressure of $0.3 \mathrm{~N} / \mathrm{mm}^{2}$. Figure 11 shows the specimens divided in half after the water penetration test. 

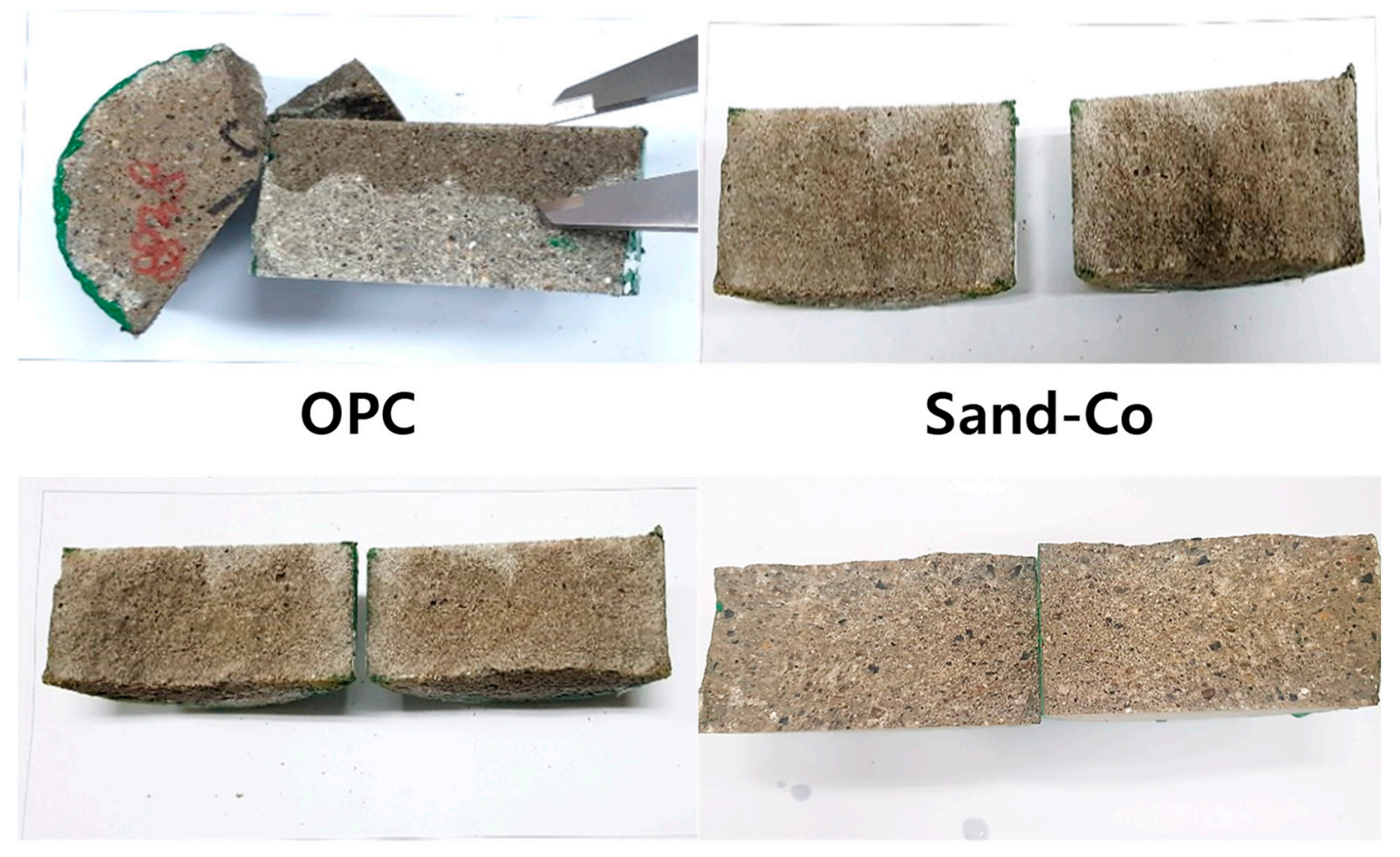

Silica-Co

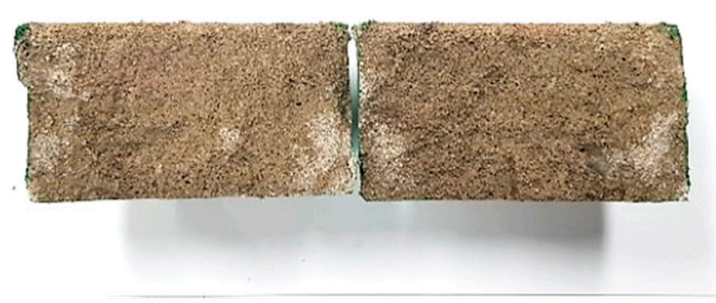

WR-In

\section{FA-Co}

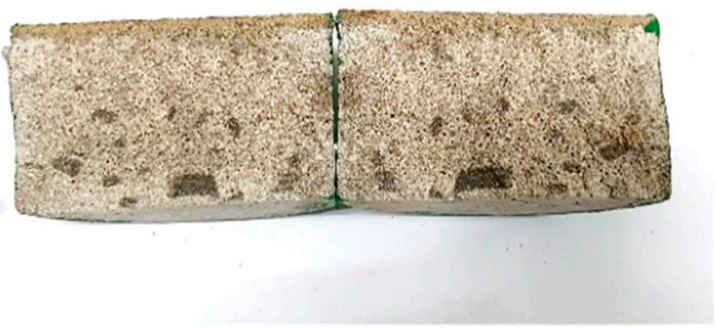

ZWR

Figure 11. Result of the water penetration test specimen.

\subsection{Result of Resistance of Concrete to Chloride Ion Penetration Test (RCPT)}

The ZWR exhibited the lowest total passing charge (Coulomb: C) followed by OPC, WR-In, FA-Co, Silica-Co, and Sand-Co. The RCPT was conducted by cutting each $\varnothing 100 \times 200 \mathrm{~mm}$ cylindrical specimen to a height of $50 \mathrm{~mm}$, coating the surface with epoxy, and fabricating three samples for each specimen. OPC showed the values ranging from 4298 to 5663, whereas Sand-Co, Silica-Co, and Fa-Co showed the values ranging from 6289 to 7414 . The WR-In specimen showed the values ranging from 5242 to 6310 , and it exhibited a lower deviation than the specimens mentioned above. The specimen that exhibited the lowest deviation was the ZWR specimen, and its standard deviation was approximately 500. The total passing charge of the ZWR specimen was significantly lower than that of OPC, which is the reference specimen. An average value of 1438 was obtained from the three tests, and this was $29 \%$ of the average value of OPC. Table 13 shows the results of RCPT conducted at 28 curing days. 
Table 13. Result of the resistance chloride ion penetration test.

\begin{tabular}{|c|c|c|c|c|c|c|}
\hline \multirow{2}{*}{$\begin{array}{c}\text { Name } \\
-\end{array}$} & \multicolumn{4}{|c|}{ Coulombs } & \multirow{2}{*}{ Penetration } & \multirow{2}{*}{$\begin{array}{c}\text { Normalized Values } \\
\text { OPC } 28 \text { Days Coulombs (\%) }\end{array}$} \\
\hline & 1st & 2nd & 3rd & Average & & \\
\hline OPC & 4298 & 5663 & 4735 & 4898 & High & 100.0 \\
\hline Sand-Co & 6550 & 7414 & 7346 & 7103 & High & 145.0 \\
\hline Silica-Co & 6289 & 6918 & 7244 & 6817 & High & 139.1 \\
\hline FA-Co & 6641 & 6469 & 7094 & 6735 & High & 137.5 \\
\hline WR-In & 6310 & 5242 & 5676 & 5743 & High & 117.2 \\
\hline ZWR & 1382 & 1518 & 1416 & 1438 & Low & 29.3 \\
\hline
\end{tabular}

The standard deviation may slightly vary depending on the conditions and time of immersing the specimens in water, but pores were not filled with the water-repellent's active ingredient for the specimens other than ZWR. It appears that the penetration and movement of the chlorides contained in water occurred in areas where water repellency was lost. The ZWR appeared to be resistant to the chloride penetration caused by water penetration because it was evenly distributed in cement mortar. In the case of the Sand-Co, Silica-Co, FA-Co, and WR-In specimens, the air content was high and pores inside them increased, and this appears to have reduced resistance to water penetration. Therefore, chlorides could move freely, and penetration resistance was low; thus, the total passing charge was much higher than that of the ZWR specimen. Figure 12 shows the results of RCPT.

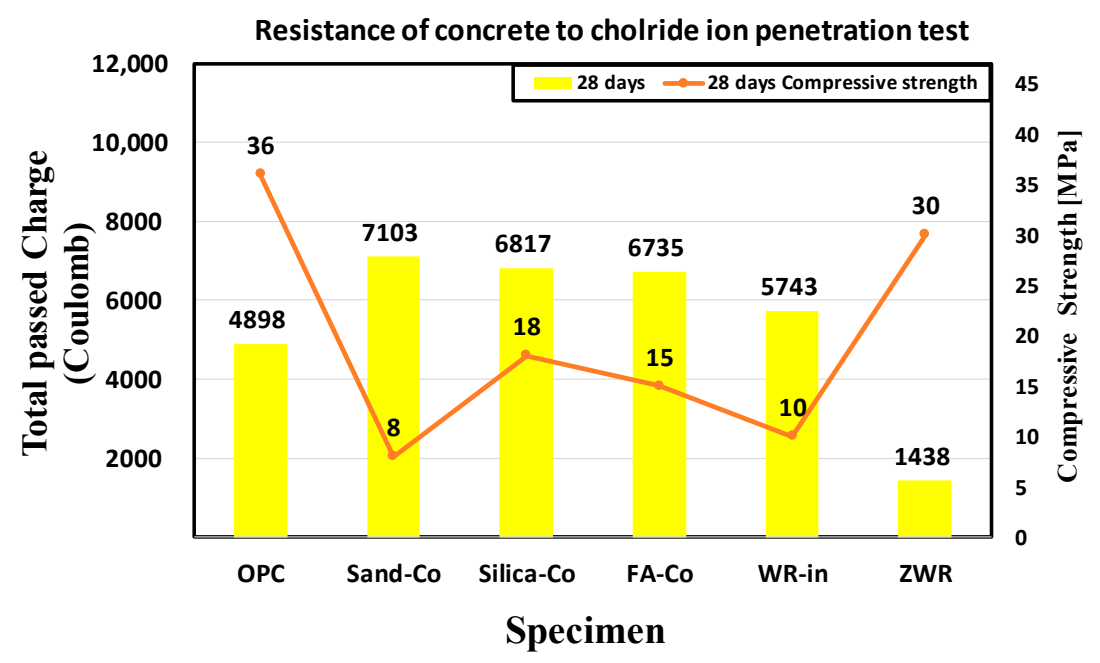

Figure 12. Result of resistance of concrete to chloride ion penetration test.

\subsection{Mercury Intrusion Porosimetry (MIP)}

When the pore structures were analyzed at 28 curing days, the pore sizes ranged from 10 to $100,000 \mathrm{~nm}$ for all the specimens. For the OPC and ZWR specimens, the micropores ranging from 10 to $100 \mathrm{~nm}$ exhibited the highest proportion and large pores ranging from 10,000 to 100,000 nm the lowest proportion. For the Sand-Co and WR-In specimens, large pores showed the highest proportion. Figure 13 shows the size and distribution of pores after the MIP test. 


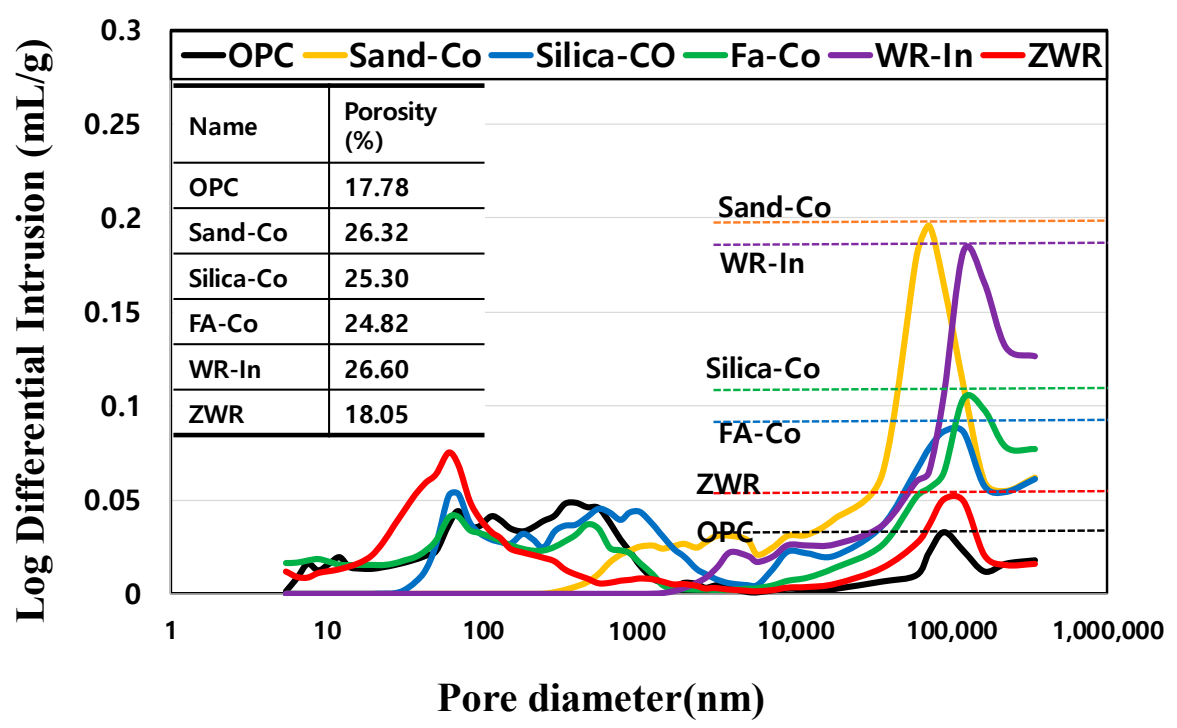

Figure 13. Results of the mercury intrusion porosimetry (MIP) test after 28 days.

When three samples were tested for each specimen, the standard deviations of OPC and ZWR were found to be less than $2 \%$ for porosity. The standard deviations of Sand-Co, Silica-Co, FA-Co, and WR-In were found to range from $6 \%$ to $7 \%$, confirming larger deviations compared to OPC and ZWR. This appears to be because the specimens did not have uniform pore sizes as some of the water-repellent's active ingredient was present and some of it was lost inside the specimens instead of being evenly dispersed. The porosity of ZWR was slightly higher than that of OPC, but it was judged that the pore structure of the ZWR specimen was improved because the water-repellent's active ingredient penetrated into the pores. It was found that the Sand-Co, Silica-Co, and FA-Co specimens had large pores. It appears that silane/siloxane was not fixed because the surface of SF and FA was smooth and spherical and had no internal pore, and that silane/siloxane was not attached to the inside of the pores in cement mortar. In addition, the water-repellent active ingredient that was not fixed to the powders did not bond with the hydration products of cement. It was confirmed that the pores in cement mortar were not filled with hydration products because hydrophobicity was formed around the clinker.

\subsection{Scanning Electron Microscope (SEM)}

The specimens cured for 7 and 28 days were analyzed using SEM. Figure 14 shows the water-repellent's active ingredient extracted from the water-based water repellent. Figure 15 shows the results of analyzing the images of the specimens at 7 curing days.

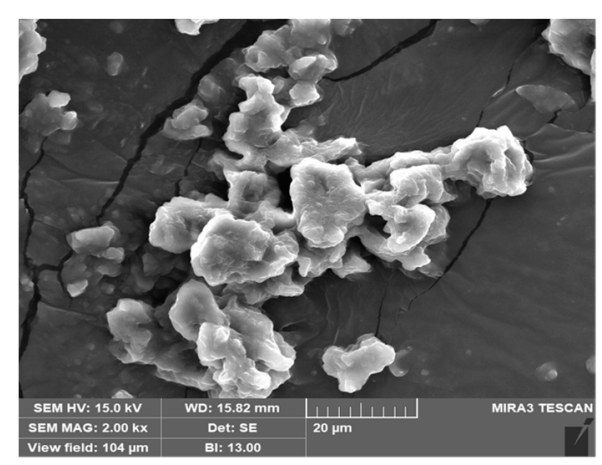

Water repellent active ingredient

Figure 14. Water repellent active ingredient. 


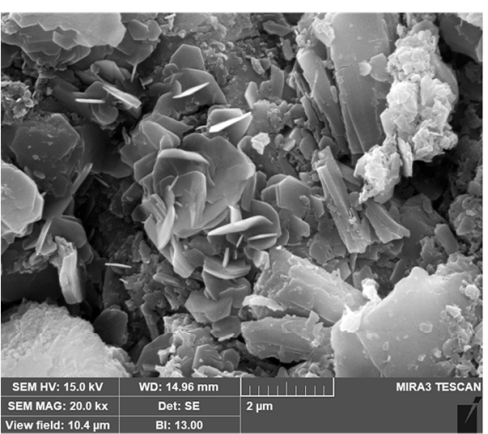

OPC

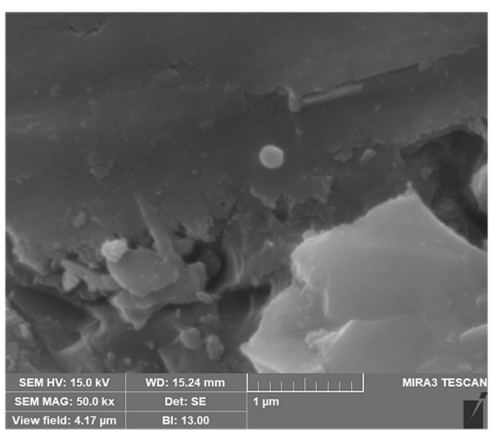

FA-Co

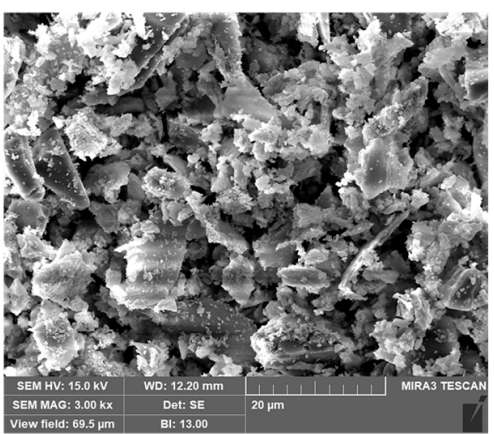

Sand-Co

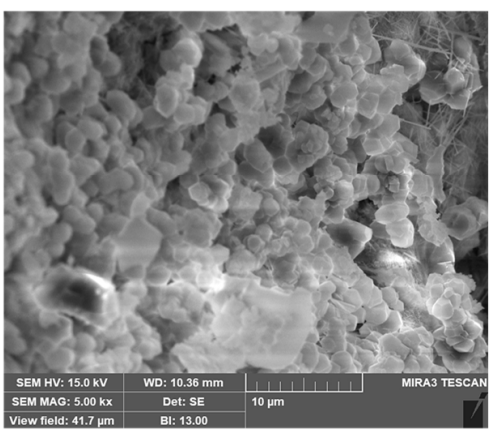

WR-In

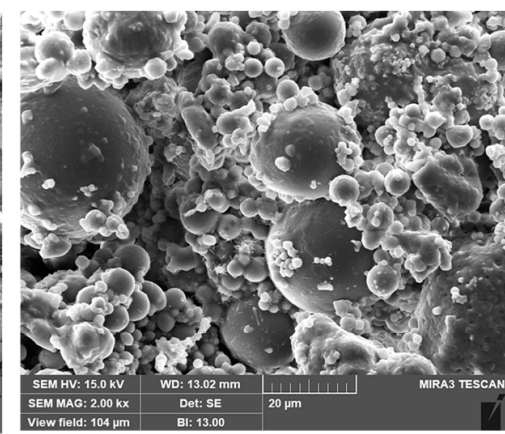

Silica-Co

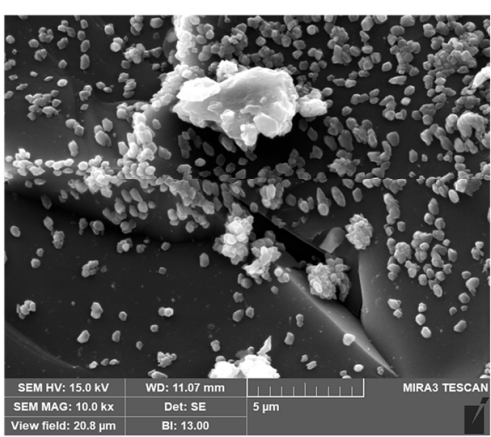

ZWR

Figure 15. Electron scanning microscope analysis after curing for 7 days.

At the OPC at 7 day of curing days, the crystals of monosulfate and $\mathrm{Ca}(\mathrm{OH})_{2}$, which are plate-type hydration products, could be confirmed. In the Sand-Co specimen, transparent and white silane/siloxane crystals were observed. The Silica-Co and FA-Co specimens had no pores, and the particles had a smooth and spherical surface and, thus, most of the water-repellent's active ingredient was separated and attached only to some of the surface. Some of the water-repellent's active ingredient appears to have been released due to the bleeding phenomenon during condensation caused by the difference in specific gravity. In addition, ettringite, a hydration product of some cement types, was observed. When the water-based water repellent was directly added to mortar, the transparent white water repellent was not evenly dispersed and appears to be aggregated at one position. In addition, the formation of ettringite was confirmed in areas without water repellency. The ZWR specimen showed natural zeolite in the form of hexagonal cubes, which was bonded with the water-repellent's active ingredient. In addition, it appears that the pores were filled as with stacked $\mathrm{Ca}(\mathrm{OH})_{2}$.

In the case of OPC at 28 curing days, calcium silicate hydrate $(\mathrm{CSH})$ gel and $\mathrm{Ca}(\mathrm{OH})_{2}$, which can be generally found in the hydration reaction, were confirmed. In the Sand-Co specimen, some hydration products, such as ettringite, were found and the presence of the white water-repellent active ingredient around the sand particles and pores was confirmed. This appears to have delayed the supply of water. In the case of Silica-Co and FA-Co, the formation of some hydration products around the spherical particles was observed, but they were not widely distributed. It appears that hydration products were partially formed due to the separation of the water-repellent's active ingredient. This is the phenomenon that generally occurs because the water-repellent's active ingredient is not fixed to powder. In the case of WR-In, more ettringite was formed compared to the Sand-Co, Silica-Co, and FA-Co specimens. As the hydration product that can be seen in the early stage of the hydration reaction was observed, it appears that the hydration reaction was significantly delayed. In the ZWR specimen, the water-repellent's active ingredient was not separated and most of it was fixed to natural zeolite, and it was confirmed that some ZWR samples were bonded with hydration products and filled the pores. Figure 16 shows the results of analyzing the images of the specimens at 28 curing days. 

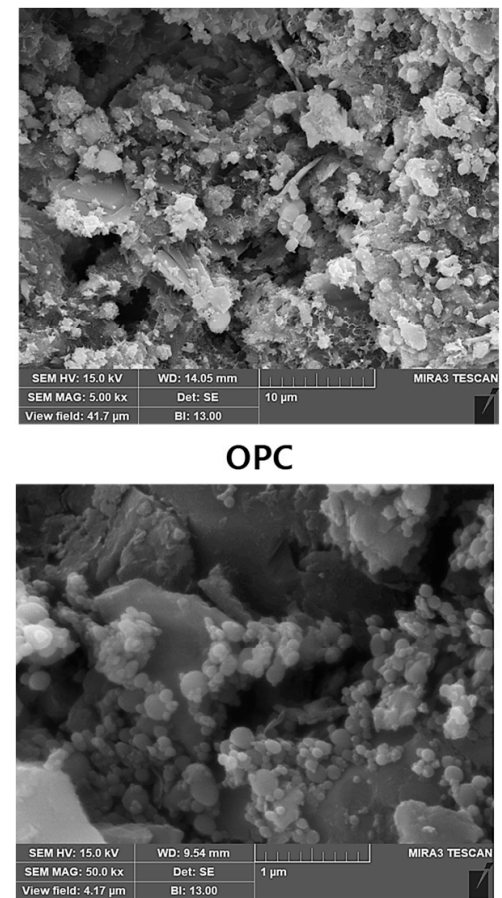

FA-Co

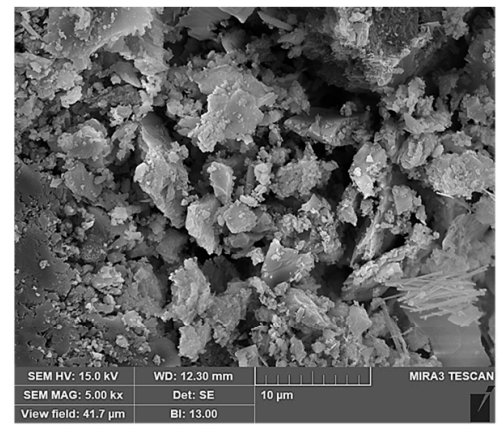

Sand-Co

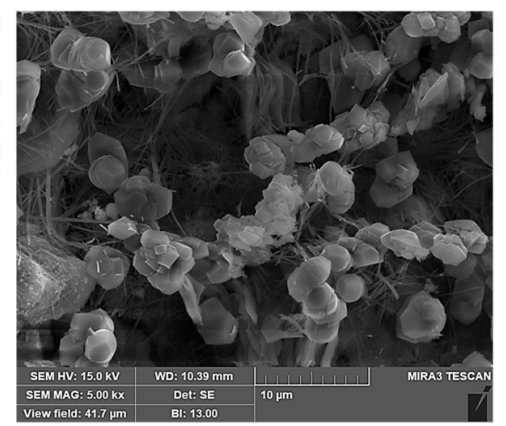

WR-In

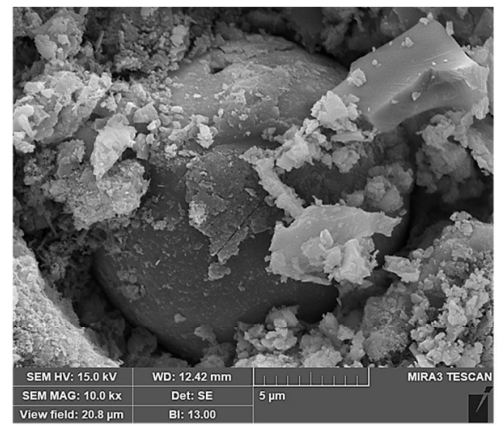

Silica-Co

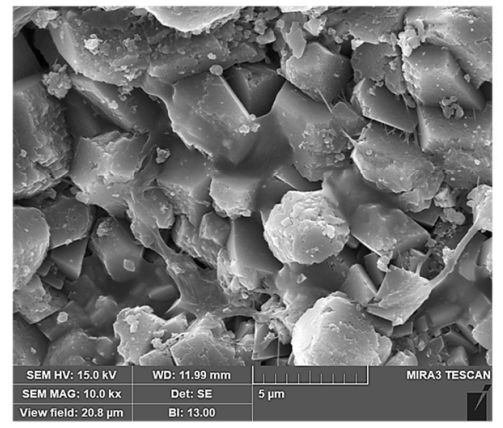

ZWR

Figure 16. Curing at 28 days and the electron scanning microscope analysis.

\section{Conclusions}

To prevent a reduction in the durability of concrete due to the presence of water, powders to which water repellency was provided, were added to cement mortar and then the physical properties' and durability's performance were examined.

It was found that the water repellent impregnated natural zeolite (ZWR) specimen exhibited lower flow and air content values compared to other specimens, and its compressive strength was $83 \%$ of that of the reference mortar. It appears that ZWR reduced pores and served as a cushion. Therefore, the strength was slightly reduced.

In the contact angle test, the results of exceeding the hydrophobicity criterion of $90^{\circ}$ were obtained in order of WR-In $\left(130^{\circ}\right)>$ ZWR $\left(124^{\circ}\right)$. It appears that the particles of the water-repellent's active ingredient in the water-repellent powders were attached to the pores in concrete and the repulsive force was generated by the surface tension of the pores.

In the water penetration test, all the specimens except for ZWR exhibited low water penetration resistance at an atmospheric pressure of $0.3 \mathrm{~N} / \mathrm{mm}^{2}$. This appears to be because the water-repellent active ingredient filled the pores, which serve as transport pathways for water, without being separated.

In the resistance chloride ion penetration test (RCPT), ZWR exhibited the low total passing charge, which was approximately $30 \%$ of that of ordinary Portland cement (OPC). It was confirmed that ZWR was also resistant to the penetration of chloride ions, which can be generated by the penetration of water.

The mercury intrusion porosimetry (MIP) results showed that the distribution and size of pores in ZWR were almost similar to those in the reference mortar.

The water-repellent's active ingredient can induce the separation of substances from cement as a different substance, but it can provide water-repellent performance by filling the pores in cement if fixed using a carrier and not discharged. In the case of fly ash (FA) and silica fume (SF), however, their smooth and spherical surface makes it difficult for them to serve as carriers, and it appears that the discharged water-repellent's active ingredient affects the initial bonding and hydration reaction. It was 
confirmed that all unreacted particles except for the particles involved in ionic reactions are factors that inhibit reactions, and that they may cause problems with compressive strength and absorptivity.

To provide water-repellent's performance to concrete using a carrier, the ability of the carrier to fix the water-repellent active ingredient is important. It is also important to improve the pore structure as the porosity and pore size are reduced by the water-repellent active ingredient. In the scope of this study, natural zeolite appears to be the most ideal carrier for providing water-repellent performance.

Author Contributions: C.B.Y. designed the work, performed the experiments, analyzed the data and wrote the initial draft of the manuscript. H.S.L. was involved in the scientific discussion, revision and finalizing the manuscript as well as in funding acquisition. All authors have read and agreed to the published version of the manuscript.

Funding: This work was supported by a National Research Foundation of Korea (NRF) grant funded by the Korean government (MSIT) (No. 2015R1A5A1037548).

Conflicts of Interest: The authors declare no conflict of interest.

\section{References}

1. Yoon, C.B.; Lee, H.S. Experimental Study on the Evaluation of Physical Performance and Durability of Cement Mortar Mixed with Water Repellent Impregnated Natural Zeolite. Materials 2020, 13, 3288. [CrossRef] [PubMed]

2. Shim, H.B.; Lee, M.S. An Experimental Study on Water Resistance of Penetrating Water Repellency of Emulsified Silicon Type Exposed to The Outdoor Environment. J. Korea Concr. Inst. 2004, 16, 477-484. [CrossRef]

3. Kalaitzaki, P.M. Hydraulic lime mortars with siloxane for waterproofing historic masonry. Cem. Concr. Res. 2007, 37, 283-290. [CrossRef]

4. Moradllo, M.K.; Sudbrink, B.; Ley, M.T. Determining the effective service life of silane treatments in concrete bridge decks. Constr. Build. Mater. 2016, 116, 121-127. [CrossRef]

5. Zhang, P.; Wittmann, F.H.; Vogel, M.; Müller, H.S.; Zhao, T. Influence of freeze-thaw cycles on capillary absorption and chloride penetration into concrete. Cem. Concr. Res. 2017, 100, 60-67. [CrossRef]

6. Park, M.J.; Lee, B.J.; Kim, J.S.; Kim, W.Y. Effect of Concrete Strength on Chloride Ion Penetration Resistance and Chemical Resistance of Concrete Coated by Siloxane-based Water Repellent. J. Korea Concr. Inst. 2018, 30, 583-590. [CrossRef]

7. Namoulniara, K.; Mahieux, P.Y.; Lux, J.; Mokhtar, A.A.; Turcry, P. Efficiency of water repellent surface treatment: Experiments on low performance concrete and numerical investigation with pore network model. Constr. Build. Mater. 2019, 227, 116638. [CrossRef]

8. Oh, B.H. Durability Design for Carbonation in Concrete Structures. J. Korea Concr. Inst. 2005, 5, 30-60.

9. Lee, J.S. Comparative Study on Repellent Ability of Silane Repellent According to Type and Treatment Method. Master's Thesis, University of Ulsan, Ulsan, South Korea, 2004.

10. Lee, S.Y.; Nam, G.Y.; Kim, J.H. Effects of Water-Repellent on the Physical Properties of Water Paint. J. Korea Inst. Build. Constr. 2004, 14, 259-265. [CrossRef]

11. Folker, H. Effective Chloride Barrier for Reinforced Concrete Structures in Order to Extend the Service-Life. In Advances in Construction Materials; Springer: Berlin/ Heidelberg, Germany, 2007; pp. 427-437.

12. Zhu, Y.G.; Kou, S.C.; Poon, C.S.; Dai, J.G.; Li, Q.Y. Influence of silane-based water repellent on the durability properties of recycled aggregate concrete. Cem. Concr. Compos. 2013, 35, 32-38. [CrossRef]

13. Wittmann, F.H.; Xian, Y.Z.; Zhao, T.J.; Beltzung, F.; Giessler, S. Drying and shrinkage of integral water repellent concrete. Restor. Build. Monum. 2006, 12, 229-242. [CrossRef]

14. Feng, H.; Le, H.T.N.; Wang, S.; Zhang, M.H. Effects of silanes and silane derivatives on cement hydration and mechanical properties of mortars. Constr. Build. Mater. 2016, 129, 48-60. [CrossRef]

15. Ma, Z.; Zhu, F.; Zhao, T. Effects of surface modification of silane coupling agent on the properties of concrete with freeze-thaw damage. KSCE J. Civ. Eng. 2018, 22, 657-669. [CrossRef]

16. Dai, J.G.; Akira, Y.; Wittmann, F.H.; Yokota, H.; Zhang, P. Water repellent surface impregnation for extension of service life of reinforced concrete structures in marine environments: The role of cracks. Cem. Concr. Compos. 2010, 32, 101-109. [CrossRef] 
17. Oh, S.K.; Ahn, S.D.; Shim, S.M. A Study on Effect of Silane Solution of Capillary Coating Type as Protection Agent of Absorption for the Durability Improvement in Concrete Surface Layer. J. Archit. Inst. Korea Struct. Constr. 2001,17, 149-158.

18. Xian, Y.Z.; Wittmann, F.H.; Zhao, T.J.; Giessler, S. Chloride penetration into integral water repellent concrete. Restor. Build. Monum. 2007, 13, 17-24. [CrossRef]

19. Wittmann, F.H.; Wittmann, A.D.A.; Wang, P.G. Capillary absorption of integral water repellent and surface impregnated concrete. Restor. Build. Monum. 2014, 20, 281-290.

20. Korean Industrial Standards. KS L. 5105, Testing Method for Compressive Strength of Hydraulic Cement Mortar; Korean Industrial Standards: Chungcheongbuk-do, Korea, 2017.

21. ASTM International. ASTM A C150, Standard Specification for Portland Cement; ASTM International: West Conshohocken, PA, USA, 2001.

22. Korean Industrial Standards. KS L. 5405, Fly Ash; Korean Industrial Standards: Chungcheongbuk-do, Korea, 2018.

23. Korean Industrial Standards. KS F. 2567, Standard Specification on Silica Fume for Concrete; Korean Industrial Standards: Chungcheongbuk-do, Korea, 2019.

24. Korean Industrial Standards. KS E. 3076, Methods for X-ray Fluorescence Spectrometric Analysis of Silica Stone and Silica Sand; Korean Industrial Standards: Chungcheongbuk-do, Korea, 2017.

25. Korean Industrial Standards. KS F. 2421, Standard Test Method for Air of Fresh Concrete by the Pressure Method (Air Receiver Method); Korean Industrial Standards: Chungcheongbuk-do, Korea, 2016.

26. Korean Industrial Standards. KS F. 2405, Standard Test Method for Compressive Strength of Concrete; Korean Industrial Standards: Chungcheongbuk-do, Korea, 2017.

27. Jung, Y.S. A Numerical Method for Determining Surface Tension of Sessile Drop. J. Korean Ceram. Soc. 1996, $33,1325-1330$.

28. Vivian, I.F.; Hejazi, V.; Kozhukhova, M.I.; Nosonovsky, M.; Sobolev, K. Self-assembling particle-siloxane coatings for superhydrophobic concrete. ACS Appl. Mater. Interfaces 2013, 5, 13284-13294. [CrossRef]

29. She, W.; Wang, X.; Miao, C.; Zhang, Q.; Zhang, Y.; Yang, J.; Hong, J. Biomimetic superhydrophobic surface of concrete: Topographic and chemical modification assembly by direct spray. Constr. Build. Mater. 2018, 181, 347-357. [CrossRef]

30. Li, G.; Yue, J.; Guo, C.; Ji, Y. Influences of modified nanoparticles on hydrophobicity of concrete with organic film coating. Constr. Build. Mater. 2018, 169, 1-7. [CrossRef]

31. Lange, A.; Hirata, T.; Plank, J. Influence of the HLB value of polycarboxylate superplasticizers on the flow behavior of mortar and concrete. Cem. Concr. Res. 2014, 60, 45-50. [CrossRef]

32. Korean Industrial Standards. KS F. 4919, Cement-Polymer Modified Waterproof Coationgs; Korean Industrial Standards: Chungcheongbuk-do, Korea, 2017.

33. ASTM International. ASTM C 1202 Electrical Indication of Concrete's Ability to Resist Chloride Ion Penetration. In Annual Book of American Society for Testing Materials Standards; ASTM International: West Conshohocken, PA, USA, 1993; Volume C04.02.

34. Korean Industrial Standards. KS F. 2711, Standard Test Method for Resistance of Concrete to Chloride Ion Penetration by Electrical Conductance; Korean Industrial Standards: Chungcheongbuk-do, Korea, 2017.

35. Cong, X.; Lu, S.; Gao, Y.; Yao, Y.; Elchalakani, M.; Shi, X. Effects of microwave, thermomechanical and chemical treatments of sewage sludge ash on its early-age behavior as supplementary cementitious material. J. Clean. Prod. 2020, 258, 120647. [CrossRef]

Publisher's Note: MDPI stays neutral with regard to jurisdictional claims in published maps and institutional affiliations.

(C) 2020 by the authors. Licensee MDPI, Basel, Switzerland. This article is an open access article distributed under the terms and conditions of the Creative Commons Attribution (CC BY) license (http://creativecommons.org/licenses/by/4.0/). 